\title{
Changes of hematological and biochemical parameters and levels of pepsinogen, histamine and prostaglandins in dairy cows affected with left displacement of the abomasum
}

\author{
O. Al-Rawashdeh, Z. Bani Ismail, A. Talafha, A. Al-Momani \\ Department of Veterinary Clinical Sciences, Faculty of Veterinary Medicine, \\ Jordan University of Science and Technology, P. O. Box 3030, Irbid 22110, Jordan
}

\begin{abstract}
The aims of this study were to determine the serum levels of pepsinogen, histamine, and prostaglandins F2 $\alpha$ and E2 in lactating dairy cows affected with left displacement of the abomasum (LDA). In addition, the hematological and serum biochemical parameters were also determined in cows affected with LDA. A total of 52 adult lactating Holstein-Friesian cows affected with LDA and 30 normal cows (control) were used. In LDA cows, the average age, BCS and body weight were $4.9 \pm 1.2$ years, $2.5 \pm 0.75$, and $525 \pm 150 \mathrm{~kg}$ respectively. The average days-in-milk (DIM) in affected cows was $14 \pm 6$ with a range between 7 to 45 days. There were no significant differences in values of rectal temperature, heart rate and respiration rate between LDA cows and control. Rumen motility was significantly $(\mathrm{p} \leq 0.05)$ decreased in LDA cows. Cows affected with LDA had significantly $(\mathrm{p} \leq 0.05)$ increased glucose levels, and decreased levels of calcium and magnesium. There were significantly $(\mathrm{p} \leq 0.05)$ increased serum levels of pepsinogen and histamine in LDA cows while levels of prostaglandin E2 were significantly decreased in comparison to those in control cows. There were no significant changes in serum levels of prostaglandin F2 $\alpha$. In the hematology analyses, there were no significant changes in cows with LDA when compared to those in control cows. This study provides evidence of a possible role for pepsinogen, histamine and prostaglandin E2 in the etiopathophysiology of LDA in dairy cows.
\end{abstract}

Key words: dairy cows, abomasal displacement, pepsinogen, histamine, prostaglandins 


\section{Introduction}

Displacement of the abomasum (DA) is one of the most common and costly diseases of high producing dairy cows (Radostits et al. 2007, Doll et al. 2009). Displacement to the left side of the rumen is the most common occurrence of this condition, but displacement to the right and right torsion or volvulus are also encountered in practice (Radostits et al. 2007, Doll et al. 2009). The condition is characterized by abomasal atony and varying degrees of gas and fluid distension (Radostits et al. 2007, Doll et al. 2009). The disease occurs worldwide with an estimated lactational incidence between 1.5 to $7 \%$ (Van Winden et al. 2003, LeBlanc 2010). The disease is accompanied by significant economic losses mainly due to loss of milk production, cost of veterinary treatment and medications and sometimes loss of the cow (Ricciotti and FitzGerald 2011). Clinically, the disease is most common in the first 4-8 weeks following parturition (Van Winden et al. 2002). Affected cows usually have partial or complete anorexia, significant reduction in milk production, secondary ketosis and ping sounds on auscultation and percussion of the left abdomen (Radostits et al. 2007).

Fully understanding the etiology and risk factors associated with increased incidence of the disease is essential for effective preventative measures. Nutritional management during the transitional period and negative energy balance in the immediate post parturient period are known to be the most important factors leading to displacement of the abomasum in dairy cows (Radostits et al. 2007, Mulligan and Doherty 2008, Doll et al. 2009, Basoglu et al. 2014). Other reported predisposing factors include genetics, neurological abomasal atony or hypomotility, hypocalcemia, and other metabolic disorders such as ketosis and fatty liver (Holtenius et al. 2000,Van Winden and Kuiper 2003). Several concomitant diseases have also been linked to the occurrence of the condition such as endometritis, metritis, mastitis, and lameness (Radostits et al. 2007).

Although changes in some of the hematology and serum biochemical parameters in dairy cows affected with LDA have been previously reported (Sevinc and Basoglu 2002, Stengärde et al. 2008, Duffield et al. 2009, Dezfouli et al. 2013, El-Attar et al. 2013). The role of many other internal factors in the etiology and pathogenesis of LDA such as hormones associated with parturition, initiation of lactation and stress hormones are not yet fully understood. Therefore, the aim of this study was to investigate a possible association between the incidence of LDA and serum concentrations of prostaglandin $\mathrm{F} 2 \alpha$, prostaglandin E2, histamine and pepsinogen in post parturient dairy cows.

\section{Materials and Methods}

\section{Case selection}

A total of 52 Holstein-Frisian lactating dairy cows confirmed to have left displacement of abomasum were used in the study. Cows were presented to the Veterinary Health Center for evaluation of possible gastrointestinal problems. Cows were selected for the study if they were diagnosed with LDA by auscultation and percussion and confirmed during surgery. In addition, 30 normal cows were matched for age and stage of lactation with the affected cows and were used as control. The history and clinical examination findings including the age, body condition score (BCS), body weight, and average days-in-milk (DIM) were recorded. All LDA and normal cows were subjected to a complete physical examination including heart rate, respiration rate, rectal temperature, rumen motility, and abdominal auscultation and percussion. Rectal palpation was performed to rule out metritis in all cows. Udder and milk secretion examination was performed by palpation and California Mastitis Test (CMT) respectively to rule out clinical and subclinical mastitis. Urine ketone bodies were detected using the Rothera test (Urine dipstick, Bj Shengshi Dotop Technology Co., China). Cows with LDA and control cows affected with other diseases such as mastitis, metritis, pneumonia, peritonitis or lameness were not included in the analyses. All selected cows with LDA were subjected to right paralumber fossa omentopexy according to a previously reported procedure (Steiner 2006). Post-operatively, cows were treated using ceftiofur hydrochloride (Excenel, Zoetis, New Jersey, USA) at $2.2 \mathrm{mg} / \mathrm{kg}$ intramuscularly once per day for 3 days, flunixin meglumine (Vet Tek, Inc., MO, USA) at $1.1 \mathrm{mg} / \mathrm{kg}$ intramuscularly once per day for 3 days. All cows were administered $500 \mathrm{ml}$ of calcium borogluconate (Norbrook Inc., Kansas, USA) subcutaneously once and 20 liters of oral fluids containing $100 \mathrm{gm}$ magnesium carbonate, $100 \mathrm{gm}$ yeast and $5 \mathrm{gm}$ calcium propionate using stomach tube before they were discharged on the same day of surgery.

\section{Laboratory analyses}

Whole blood samples were collected via coccygeal venipuncture using vacutainer needle and vacutainer tubes from each cow before surgery. At least $10 \mathrm{mls}$ of blood were collected and placed in EDTA-containing and plain blood collection tubes for hematology and serum biochemical analyses using previously published methods (Thrall et al. 2004). The hematology analyses included determination of the total white 
Table 1. Mean \pm SD of clinical and epidemiological data of Holstein-Friesian dairy cows affected with left displacement of abomasum.

\begin{tabular}{lccc}
\hline \multicolumn{1}{c}{ Parameters } & $\begin{array}{c}\text { LDA cows } \\
(\mathrm{n}=52)\end{array}$ & $\begin{array}{c}\text { Control cows } \\
(\mathrm{n}=30)\end{array}$ & $\begin{array}{c}\text { Percentage of cases within } \\
\text { the normal range }\end{array}$ \\
\hline Age & $4.9 \pm 1.2$ & $4.5 \pm 1$ & NA \\
\hline Body condition score & $2.5 \pm 0.75$ & $2.75 \pm 0.75$ & NA \\
\hline Weight $(\mathrm{kg})$ & $525 \pm 150$ & $580 \pm 90$ & NA \\
\hline Average days in milk & $14 \pm 6$ & $16 \pm 4$ & NA \\
\hline Body temperature $\left({ }^{\circ} \mathrm{C}\right)$ & $38.2 \pm 0.50$ & $38.5 \pm 0.10$ & 88 \\
\hline Heart rate $(/ \min )$ & $70 \pm 2$ & $64 \pm 4$ & 92 \\
\hline Respiratory rate $(/ \mathrm{min})$ & $26 \pm 4$ & $22 \pm 1$ & 99 \\
\hline Ruminal motility $(\mathrm{min})$ & $2 / 2^{*}$ & $3 / 2$ & 98 \\
\hline
\end{tabular}

NA: Not Applicable

$* \mathrm{p} \leq 0.05$

Table 2. Hematology parameters in Holstein-Friesian dairy cows affected with left displacement of the abomasum.

\begin{tabular}{lccc}
\hline \multicolumn{1}{c}{ Parameters } & $\begin{array}{c}\text { LDA cows } \\
(\mathrm{n}=52)\end{array}$ & $\begin{array}{c}\text { Control cows } \\
(\mathrm{n}=30)\end{array}$ & $\begin{array}{c}\text { Percentage of cases within } \\
\text { the normal range }\end{array}$ \\
\hline $\mathrm{WBC}\left(\mathrm{x} 10^{3}\right.$ cells $\left./ \mu \mathrm{l}\right)$ & $7 \pm 1.2$ & $10 \pm 2.0$ & 98 \\
\hline $\mathrm{RBC}\left(\mathrm{x} 10^{6}\right.$ cells $\left./ \mu \mathrm{l}\right)$ & $6.5 \pm 0.7$ & $7.0 \pm 0.5$ & 92 \\
\hline $\mathrm{HB}(\mathrm{g} / \mathrm{dl})$ & $10 \pm 0.9$ & $11 \pm 1.3$ & 99 \\
\hline $\mathrm{PCV} \%$ & $33 \pm 4.5$ & $28 \pm 2.5$ & 94 \\
\hline $\mathrm{MCV}(\mathrm{fl})$ & $51 \pm 6$ & $47 \pm 5.0$ & 99 \\
\hline $\mathrm{MCH}(\mathrm{pg})$ & $16 \pm 2$ & $14 \pm 2.0$ & 98 \\
\hline $\mathrm{MCHC}(\mathrm{g} / \mathrm{dl})$ & $31 \pm 2$ & $30 \pm 1.5$ & 95 \\
\hline Platelets $\left(\mathrm{x} 10^{3}\right.$ cells $\left./ \mu \mathrm{l}\right)$ & $367-94$ & $336 \pm 68$ & 99 \\
\hline
\end{tabular}

WBC: white blood cell count; RBC: red blood cell count; HB: hemoglobin concentration; PCV: packed cell volume; MCV: mean corpuscular volume; MCHC: mean corpuscular hemoglobin concentration

Table 3. Serum biochemical analyses parameters in Holstein-Friesian dairy cows affected with left displacement of the abomasum.

\begin{tabular}{lccc}
\hline \multicolumn{1}{c}{ Parameters } & $\begin{array}{c}\text { LDA cows } \\
(\mathrm{n}=52)\end{array}$ & $\begin{array}{c}\text { Control cows } \\
(\mathrm{n}=30)\end{array}$ & $\begin{array}{c}\text { Percentage of cases within } \\
\text { the normal range }\end{array}$ \\
\hline AST $(\mathrm{IU} / \mathrm{L})$ & $41 \pm 4.7$ & $34 \pm 2.5$ & 87 \\
\hline ALT $(\mathrm{IU} / \mathrm{L})$ & $117 \pm 25$ & $137 \pm 40$ & 90 \\
\hline ALP $(\mathrm{IU} / \mathrm{L})$ & $47 \pm 14$ & $42 \pm 17$ & 96 \\
\hline Total protein $(\mathrm{g} / \mathrm{L})$ & $82 \pm 28$ & $82 \pm 12$ & 89 \\
\hline Albumin $(\mathrm{g} / \mathrm{L})$ & $27 \pm 8$ & $30 \pm 5$ & 92 \\
\hline BUN $(\mathrm{mg} / \mathrm{dL})$ & $14 \pm 3.5$ & $14 \pm 3.7$ & 83 \\
\hline Creatinine $(\mathrm{mg} / \mathrm{dL})$ & $1.5 \pm 1.0$ & $1.2 \pm 0.6$ & 88 \\
\hline Glucose $(\mathrm{mmol} / \mathrm{L})$ & $9 \pm 1.40^{*}$ & $8.5 \pm 1.6$ & 54 \\
\hline Calcium $(\mathrm{mg} / \mathrm{dL})$ & $7 \pm 3^{*}$ & $9 \pm 1$ & 45 \\
\hline Magnesium $(\mathrm{mg} / \mathrm{dL})$ & $1.8 \pm 0.6^{*}$ & $2.4 \pm 0.7$ & 67 \\
\hline Sodium $(\mathrm{mmol} / \mathrm{L})$ & $140 \pm 68$ & $153 \pm 9$ & 87 \\
\hline Chloride $(\mathrm{mmol} / \mathrm{L})$ & $99 \pm 29$ & $102 \pm 4$ & 88 \\
\hline Potassium $(\mathrm{mmol} / \mathrm{L})$ & $4.0 \pm 1.0$ & $5 \pm 0.9$ & 89 \\
\hline
\end{tabular}

AST: aspartate aminotransferase; ALT: alanine aminotransferase; ALP: alkaline phosphatase; BUN: blood urea nitrogen * $\mathrm{p} \leq 0.05$ 
Table 4. Serum concentrations of pepsinogen, histamine, prostaglandin F2 $\alpha$ and prostaglandin E2 in Holstein-Friesian dairy cows affected with left displacement of the abomasum.

\begin{tabular}{lccc}
\hline \multicolumn{1}{c}{ Parameters } & $\begin{array}{c}\text { LDA cows } \\
(\mathrm{n}=52)\end{array}$ & $\begin{array}{c}\text { Control cows } \\
(\mathrm{n}=30)\end{array}$ & $\begin{array}{c}\text { Percentage of cases within } \\
\text { the normal range }\end{array}$ \\
\hline Pepsinogen $(\mathrm{ng} / \mathrm{mL})$ & $340 \pm 169^{*}$ & $177 \pm 57$ & 55 \\
\hline Histamine $(\mathrm{ng} / \mathrm{mL})$ & $80 \pm 46^{*}$ & $39 \pm 15$ & 57 \\
\hline PGF2 $\alpha(\mathrm{ng} / \mathrm{mL})$ & $4.4 \pm 1.4$ & $4 \pm 1.5$ & 82 \\
\hline PGE2 $(\mathrm{Pg} / \mathrm{mL})$ & $514 \pm 194^{*}$ & $1223 \pm 580$ & 33 \\
\hline
\end{tabular}

* $\mathrm{p} \leq 0.05$

blood cell count (WBC), red blood cell count (RBC), hemoglobin concentration $(\mathrm{Hb})$, packed cell volume (PCV), mean corpuscular volume (MCV), and mean corpuscular hemoglobin concentration (MCHC) using an electronic cell counter (Scil Vet ABC Hematology Analyzer, Scil Animal Care Company, USA). For the serum biochemical analyses, serum was obtained by allowing samples to clot at room temperature and then centrifuged at $3000 \mathrm{~g}$ for 10 minutes. Theserum was then analyzed to determine total protein (TP), albumin, glucose, blood urea nitrogen (BUN), creatinine, aspartate transaminase (AST), alanintransferase (ALT), alkaline phosphatase (ALP), calcium $(\mathrm{Ca})$, potassium $(\mathrm{K})$, magnesium $(\mathrm{Mg})$, sodium $(\mathrm{Na})$, and chloride $(\mathrm{Cl})$ using previously published methods (Thrall et al. 2004).

Serum concentrations of prostaglandin F2 $\alpha$ (Bluegene Biotech, Shanghai, China), prostaglandin E2 (R\&D Systems, Shanghai, China), histamine (Bluegene Biotech, Shanghai, China) and pepsinogen (Bluegene Biotech, Shanghai, China) were determined using commercially available ELISA kits according to manufacturer recommendations.

\section{Statistical analysis}

Data were expressed in means \pm SD. Analysis to compare various parameters of hematology, serum biochemistry and hormones between affected cows and control cows was performed using SPSS software (SPSS Inc., Chicago, Illinois). The data was tested for normality and then a parametric independent t-test was then used to investigate significant differences between control and affected groups. Values of $p \leq 0.05$ were considered significant.

\section{Results}

The clinical and epidemiological data from the 52 Holstein-Friesian dairy cows affected with left displacement of abomasum are presented in Table 1. All cows had reportedly lost appetite 24 to 48 hours before admission to the clinic. There was slight to moderate loss of milk production the day before surgery. The average age, BCS and body weight of cows with LDA were $4.9 \pm 1.2$ years, $2.5 \pm 0.75$, and $525 \pm 150 \mathrm{~kg}$ respectively. The average days-in-milk (DIM) in affected cows was $14 \pm 6$ with a range between 7 to 45 days. There were no significant differences in values of rectal temperature, heart rate and respiration rate between LDA cows and control. Rumen motility was significantly $(\mathrm{p} \leq 0.05)$ decreased in LDA cows. Tables 2 and 3 show values of hematology and serum biochemical parameters in cows affected with LDA. In the hematology analysis, there were no significant changes in any of the parameters in cows with LDA when compared to those in control cows. In the serum biochemical analysis, cows affected with LDA had a significantly $(\mathrm{p} \leq 0.05)$ increased glucose levels, and decreased levels of calcium and magnesium. Table 4 shows the serum concentrations of pepsinogen, histamine, prostaglandin $F 2 \alpha$ and prostaglandin E2 in dairy cows affected with LDA. There were significantly $(p \leq 0.05)$ increased serum levels of pepsinogen and histamine in LDA cows, while levels of prostaglandin E2 were significantly decreased in comparison to those in control cows. There were no significant changes in serum levels of prostaglandin $\mathrm{F} 2 \alpha$.

\section{Discussion}

Left displacement of the abomasum is one of the most common diseases of the post parturient period of dairy cows. As previously reported, cows with LDA in this study had normal rectal temperature, heart rate and respiration rate (Radostits et al. 2007, Doll et al. 2009). However, rumen motility was significantly $(\mathrm{p} \leq 0.05)$ decreased in LDA cows. Cows in early lactation suffer a significant reduction in feed intake and negative energy balance, which have a potent suppressor effect on the rumen predisposing the cow to the occurrence of LDA (Van Winden et al. 2002, Stengärde et al. 2008). Subclinical hypocalcemia is 
common in post parturient dairy cows, which also may explain rumen and abomasal atony in cows with LDA (Van Winden and Kuiper 2003). Changes in feeding behavior or management in the transition period has been implicated as a main factor in the occurrence of rumen and abomasal atony leading to LDA in the immediate postpartum period. Feeding high concentrates or high moisture corn silage in early lactation is believed to inhibit motility, gas accumulation, dilatation and atony (Van Winden et al. 2002, Van Winden and Kuiper 2003, Stengärde et al. 2008).

In the hematology analyses, unlike the results reported here, others have found a significant increase in the hematocrit and hemoglobin concentration in cows with LDA which was attributed to hemoconcentration and dehydration (Van Winden et al. 2003, Zadnik 2003). This dehydration could be the result of a lack of intake and failure to absorb fluids from the proximal gastrointestinal tract due to partial or complete obstruction. In the leukogram, some researchers found increased numbers of leukocytes and neutrophelia (Stengärde et al. 2010). They attributed these changes to immunological responses against endotoxemia and abomasitis that may occur secondarily to LDA (Stengärde et al. 2010). In the study reported here, only otherwise healthy cows were included in the study. Although in this study, a tendency for higher platelet count was detected in LDA cows, this change was statistically not significant. These findings in fact are in contrast to previously reported findings where lower platelet counts were observed in cows affected with LDA; this was attributed to possible coagulopathy associated with the displacement of the abomasum (Sobiech et al. 2008). This discrepancy could be explained by the difference in health status of cows presented here.

Cows with LDA suffer a significant negative energy balance and metabolic challenges that may affect liver functions and other biochemical parameters (Van Winden et al. 2003). Cows in this study only had a significantly $(\mathrm{p} \leq 0.05)$ increased levels of serum glucose, and a decreased serum levels of calcium and magnesium (Table 3). An elevated plasma glucose level can be considered as a potential risk factor in the pathogenesis of left displacement of the abomasum.

As mentioned previously, hypocalcemia is common in postpartum cows and is considered a major predisposing factor for LDA. Cows with LDA commonly have hypochloremic, hypokalemic metabolic alkalosis (Van Winden et al. 2002, Van Winden et al. 2003) which is attributed to the lack of intake of potassium-rich forages and sequestration of chloride in the abomasums. The severity of these changes is related to the degree of anorexia, degree of obstruction and duration of the disease. In the study reported here, there were no significant changes in serum concentrations of potassium and chloride and therefore metabolic alkalosis was not significant.

Abomasal ulcers are a common consequence of prolonged LDA in high producing dairy cows with a poor survival rate (Radostits et al. 2007, Doll et al. 2009). In dairy cows, it is common to have mild to moderate abomasal mucosal epithelial damage with no apparent clinical symptoms. However, in severe cases, fatal hemorrhage or diffuse peritonitis may occur leading to the death of the cow (Radostits et al. 2007, Doll et al. 2009). Pepsinogen is converted to the proteolytic enzyme pepsin in an acidic environment in the abomasum. Serum concentrations of pepsinogen have been indicated as a simple test to aid the diagnosis of abomasal epithelial damage in cows and small ruminants (Radostits et al. 2007, Doll et al. 2009). Results of this study confirm that serum pepsinogen activities were significantly $(\mathrm{p} \leq 0.05)$ higher in cows with LDA than in control cows, which indicates serious damage to the abomasal wall in those cows (Table 4).

Histamine is a 2-(4-imidazolyl)-ethylamine short-acting amine produced by many cells in the body (Smolinska et al 2014). Although, histamine is known to mediate the immediate hypersensitivity reaction in the body, its role in sites of local inflammation and in damaged tissues is not fully understood (Smolinska et al. 2014). In the gastrointestinal tract, histamine levels can be affected by the host allergic or inflammatory responses, altered activity of digestive enzymes, dietary intake, and microbial processes (Smolinska et al. 2014). Histamine also can influence the abomasal tone and motility patterns in cows with endotoxemia (Basoglu et al. 2014). It has been found that endotoxins and mediators of inflammation such as histamine are released in excessive amounts in cows with acute metritis, mastitis and laminitis, which leads to abomasal atony and distension (Sexton et al. 2007). In this study, although careful physical examination did not reveal a source of acute inflammation or endotoxemia, the significant increase $(\mathrm{p} \leq 0.05)$ of serum concentrations of histamine may indicate a possible role for histamine in the pathogenesis of LDA in cows. Abomasitis and ulcer formation may be a direct result of locally increased histamine levels in these cases.

Prostaglandins are potent proinflammatory agents that are derived from cell wall arachidonic acid (Ricciotti and FitzGerald 2011). Physiological functions of prostaglandins are many, including sustaining homeostatic functions as well as mediating pathogenic mechanisms, including non-specific inflammatory responses (Ricciotti and FitzGerald 2011). It has been found that the biosynthesis of prostaglandins signifi- 
cantly increases in inflamed tissue and this leads to the appearance of the cardinal signs of acute inflammation (Ricciotti and FitzGerald 2011).

Although there are several members of prostaglandins, only 2 of the most common molecules with a possible relationship to LDA in cows (PGE2 and PGF2 $\alpha$ ) were investigated in this study (Table 4). PGE2 is an abundant molecule in the body and is well characterized in different animal species (Ricciotti and FitzGerald 2011). PGE2 is known to regulate various immune responses, blood pressure, gastrointestinal integrity, and fertility (Ricciotti and FitzGerald 2011). PGE2 is known to exert a dual function; as a pro-inflammatory and anti-inflammatory agent, both are produced via regulation of receptor gene expression in relevant tissues (Ricciotti and FitzGerald 2011). In this study, concentrations of prostaglandin E2 were significantly decreased in LDA cows in comparison to those in control cows. It is, however, difficult to interpret our results regarding the role of PGE2 in the pathogenesis of LDA.

On the other hand, PGF2 $\alpha$ is abundant mainly in the female reproductive system. It plays an important role in ovulation, luteolysis, and contraction of uterine smooth muscle and initiation of parturition (Ricciotti and FitzGerald 2011). Furthermore, in recent studies PGF2 $\alpha$ was found to play an important role in renal function, contraction of arteries, myocardial dysfunction, brain injury and pain (Ricciotti and FitzGerald 2011). In this study there were no significant changes in PGF2 $\alpha$ concentrations in LDA cows (Table 4). Further studies may be warranted to delineate the exact roles of prostaglandins E2 and F2 $\alpha$ on the cellular level in the damage that may occur in the abomasal wall in cases of LDA, especially those that do not survive or develop abomasal ulcers.

\section{Acknowledgments}

The authors would like to thank the Deanship of Research at Jordan University of Science and Technology for sponsoring this project.

\section{References}

Basoglu A, Baspinar N, Coskun A (2014) NMR-based metabolomic evaluation in dairy cows with displaced abomasum. Turk J Vet Anim Sci 38: 325-330.

Dezfouli MM, Eftekhari Z, Sadeghian S, Bahounar A, Jeloudari M (2013) Evaluation of hematological and biochemical profiles in dairy cows with left displacement of the abomasum. Comp Clin Path 22: 175-179.

Doll K, Sickinger M, Seeger T (2009) New aspects in the pathogenesis of abomasal displacement. Vet J 181: 90-96.
Duffield TF, Lissemore KD, McBride BW, Leslie KE (2009) Impact of hyperketonemia in ear-ly lactation dairy cows on health and production. J Dairy Sci 92: 571-580.

El-Attar HM, Yassein M, Abd El-Raof, Ghanem MM (2007) Alterations in the clinical, hematological and biochemical pictures in abomasal displacement in cows in Egypt. Vet Med J 102-109.

Holtenius K, Sternbauer K, Holtenius P (2000) The effect of the plasma glucose level on the abomasal function in dairy cows. J Anim Sci 78: 1930-1935.

LeBlanc S (2010) Monitoring metabolic health of dairy cattle in the transition period. J Reprod Dev 56: S29-35.

Mulligan FJ, Doherty ML (2008) Production diseases of the transition cow. Vet J 176: 3-9.

Radostits OM, Gay CC, Hinchcliff KW, Constable PD (2007) Veterinary medicine - a textbook of the diseases of cattle, horses, sheep, pigs and goats, $10^{\text {th }}$ ed., Elsevier Health Sciences.

Ricciotti E, FitzGerald GA (2011) Prostaglandins and Inflammation. Arterioscler Thromb Vasc Biol 31: 986-1000.

Sevinc M, Ok M, Basoglu A (2002) Liver function in dairy cows with abomasal displacement. Revue Med Vet 153: 477-480.

Sexton MF, Buckley W, Ryan E (2007) A study of 54 cases of left displacement of the abomasum. Ir Vet $\mathrm{J}$ 60: 605-609.

Smolinska S, Jutel M, Crameri R, O’Mahony L (2014) Histamine and gut mucosal immune regulation. Allergy 69: 273-281.

Sobiech P, Radwińska J, Krystkiewicz W, Snarska A, Stopyra A (2008) Changes in the coagulation profile of cattle with left abomasal displacement. Pol J Vet Sci 11: 301-306.

Stengärde L, Holtenius K, Trdven M, Hultgren J, Niskanen $\mathrm{R}$, Emanuelson U (2010) Blood profiles in dairy cows with displaced abomasum. J Dairy Sci 93: 4691-4699.

Stengärde L, Traven M, Emanuelson U, Holtenius K, Hultgren J, Niskanen R (2008) Metabolic profiles in five high-producing Swedish dairy herds with a history of abomasal displacement and ketosis. Acta Vet Scand 50: $31-42$.

Steiner A (2006) Surgical treatment of the left displacement of the abomasum an update. XXIV World Buiatrics Congress, Nice, France.

Thrall MA, Baker DC, Campbell TW, Denicola DB, Fettman MJ, Lassen DE, Rebar A, Weiser G (2004) Veterinary hematology and clinical chemistry. Lippincott Williams \& Wilkins.

Van Winden SC, Kuiper R (2003) Left displacement of the abomasum in dairy cattle: Recent development in epidemiological and etiological aspects. Vet Res 34: 47-56.

Van Winden SC, Jorritsma R, Muller KE, Noordhuizen JP (2003) Feed intake, milk yield, and metabolic parameters prior to left displaced abomasum in dairy cows. J Dairy Sci 86: 1465-1471.

Van Winden SC, Muller KE, Kuiper R, Noordhuizen JP (2002) Studies on the $\mathrm{pH}$ value of abomasal contents in dairy cows during the first 3 weeks after calving. J Vet Med A 49: 157-160.

Zadnik T (2003) A comparative study of the hema-to-biochemical parameters between clinically healthy cows and cows with displacement of the abomasum. Acta Vet Beog 53: 297-309. 